\title{
Effect of Intravitreal Bevacizumab in Macular Edema Caused by Branch Retinal Vein Occlusion
}

\author{
Imran Ahmad, Mubashir Rehman, Mir Ali Shah, Irfan Aslam Khattak
}

Pak J Ophthalmol 2019, Vol. 35, No. 1

See end of article for

authors affiliations

Correspondence to:

Mubashir Rehman

MBBS, FCPS, Assistant Professor,

Department of Ophthalmology,

Nowshera Medical College/Qazi

Hussain Ahmad Medical Complex,

Nowshera.

Email:

drmubashirrehman78@gmail.com
Purpose: To evaluate the effect of intra-vitreal bevacizumab in macular edema caused by branch retinal vein occlusion.

Study Design: Interrupted time series study.

Place and Duration of Study: Department of Ophthalmology Hayatabad Medical Complex, Peshawar and department of Ophthalmology Lady Reading Hospital Peshawar from $1^{\text {st }}$ July 2016 to $31^{\text {st }}$ December 2016.

Material and Methods: There were 60 patients included in the study. All patients with macular edema due to BRVO visible clinically and evident on SDOCT and visual acuity of less than $6 / 9$ were included in the study. Patients who used other intra-vitreal drug for macular edema, those with surgery in the same eye and those with macular laser for macular edema were excluded from the study. All patients were given intra-vitreal $0.05 \mathrm{ml}$ bevacizumab injection every month for 6 months. After 6 months OCT was repeated. At each monthly visit VA was measured and fundoscopy was done. Follow up of all patients was at six months.

Results: Our study included 60 patients with mean age of $54.42 \pm 9.19$ years. The mean baseline central macular thickness was $427.06 \mu$ with SD $\pm 63.54 \mu$. After 6 months significant improvement in visual acuity was documented. Also marked reduction in central macular thickness was noted after six months with mean of $327.44 \mu$ with $S D \pm 55.55 \mu$.

Conclusion: Intra-vitreal bevacizumab is an effective treatment for macular edema caused by BRVO in terms of both anatomic and visual improvement.

Key words: Branch retinal vein occlusion, bevacizumab, macular edema.
B ranch retinal vein occlusion is not an uncommon condition that occurs in patients with underlying systemic illness like arteriosclerosis and hypertension. It is the second most common cause of macular edema after diabetes ${ }^{1}$. BRVO is caused by focal occlusion of a retinal vein usually at an arteriovenous crossing, where, mostly, the artery is passing superficial to the vein ${ }^{2}$. Narrowing of vascular lumen results in alteration in laminar blood flow and endothelial damage. The prevalence of BRVO is 4.42 per 1,000 and accounts for about $80 \%$ of retinal venous occlusions $^{3}$.
The main cause of visual impairment in BRVO is macular edema ${ }^{4}$. The exact pathogenesis of macular edema in patients with BRVO is not clearly understood, but multiple factors are supposed to be responsible for this, including increased hydrostatic venous pressure, abnormalities in endothelium tight junction, increased concentration of inflammatory cytokines, and vascular permeability factors ${ }^{5}$. Different studies have shown that in eyes with BRVO there is a significantly elevated level of vascular endothelial growth factor (VEGF) which is considered to be the major contributor to macular edema. The severity of 
macular edema in BRVO is directly related with an increase in VEGF levels ${ }^{6}$. On the basis of these findings, inhibition of VEGF is considered to be a more scientific approach in treating patients with macular edema due to BRVO.

Bevacizumab (Avastin, Genentech; Roche, Basil, Switzerland) is a full-length, humanized, recombinant antibody that binds to all isoforms of VEGF-A and has been used extensively off-label to treat macular edema associated with BRVO. Different studies have shown that intra-vitreal bevacizumab reduces macular thickness and improves visual acuity in $\mathrm{BRVO}^{7,8}$.

Literature search has demonstrated the efficacy of ranibizumab on macular edema due to BRVO but very limited data is available for bevacizumab. Purpose of our study was to find out the efficacy of bevacizumab in the treatment of macular edema caused by BRVO.

\section{MATERIAL AND METHODS}

A total of sixty patients were included in our study. All the patients were screened following the inclusion criteria which included macular edema due to BRVO visible clinically through indirect ophthalmoscopy through slit lamp and $78 \mathrm{D}$ lens, macular edema of more than $250 \mu$ measured on Spectral domain optical coherence tomography and visual acuity of less than $6 / 9$ on Snellen visual acuity chart. Patients who had previous history of other intra-vitreal drug injection for macular edema, those with history of surgery in the same eye, history of scatter or macular laser for edema and patients with other macular diseases like age related macular degeneration were excluded from the study. All the patients underwent detailed ocular examination including visual acuity, anterior segment examination, dilated fundus examination and measurement of intra ocular pressure. SD-OCT was performed at baseline to measure the amount of macular edema and fundus fluorescein angiography was performed to check the macular perfusion.

All the patients were given intravitreal $0.05 \mathrm{ml}$ (1.25 mg) bevacizumab injection using 30 gauge needle in the operation theater under sterile conditions using topical anesthesia. Povidone-iodine 5\% solution was used to clean the periocular region. Injections were given monthly for the first 6 months. After 6 months OCT was repeated to check for macular thickness, if macular thickness was more than $250 \mu$, the injections were continued. At each monthly visit VA was measured and fundoscopy was done. All patients were followed for at least six months.
Effectiveness was determined in terms of improvement in visual acuity of at least two lines on Snellen visual acuity chart from baseline visual acuity and decrease in macular thickness on SD-OCT of 200 microns from baseline macular thickness after 6 months.

Data analysis was done using SPSS version 20.0. Quantitative variables include age, central macular thickness and visual acuity; and qualitative variables include gender. Mean \pm standard deviation was calculated for quantitative variables; percentage and proportion was calculated for qualitative variables.

\section{RESULTS}

A total of sixty patients were included in our study with age ranges from 42 years to 78 years with mean age of $54.42 \pm 9.19$ years. Table 1 shows age distribution of patients.

Table 1: Age Distribution.

\begin{tabular}{|ccc|}
\hline Age & Frequency & Percentage \\
\hline $41-50$ Years & 12 & $20.00 \%$ \\
$51-60$ Years & 22 & $36.67 \%$ \\
$61-70$ Years & 18 & $30.00 \%$ \\
$71-80$ Years & 8 & $13.33 \%$ \\
Total & 60 & $100 \%$ \\
\hline
\end{tabular}

Mean age was 54.42 years with $S D \pm 9.19$

Gender distribution among patients was analyzed as $38(63.33 \%)$ patients were male while $22(36.67 \%)$ patients were female.

All the patients received intravitreal injections of $0.05 \mathrm{ml}(1.25 \mathrm{mg})$ of bevacizumab monthly injections. Table 2 and table 3 shows baseline visual acuity and central macular thickness respectively.

Table 2: Base Line VA ( $\mathrm{n}=60$ eyes).

\begin{tabular}{|lcc|}
\hline Base line VA & Frequency & Percentage \\
\hline$<6 / 36$ & 4 & 6.66 \\
$6 / 36-6 / 18$ & 31 & $51.67 \%$ \\
$6 / 24-6 / 12$ & 13 & $21.67 \%$ \\
$6 / 18-6 / 9$ & 12 & $20.00 \%$ \\
Total & 60 & $100 \%$ \\
\hline
\end{tabular}


Table 3: Base Line OCT ( $\mathrm{n}=60$ eyes).

\begin{tabular}{|lcc|}
\hline Base Line OCT & Frequency & Total \\
\hline$>500 \mu$ & 6 & $10.00 \%$ \\
$400-500 \mu$ & 32 & $53.34 \%$ \\
$300-400 \mu$ & 18 & $30.00 \%$ \\
$200-300 \mu$ & 4 & $6.66 \%$ \\
Total & 60 & $100 \%$ \\
\hline
\end{tabular}

Mean baseline OCT was $427.06 \mu$ with SD $\pm 63.54 \mu$

After 6 months significant improvement in visual acuity was documented (table 4). Similarly central macular thickness also reduced (table 5).

Table 4: VA at 6 months ( $\mathrm{n}=60$ eyes).

\begin{tabular}{|lcc|}
\hline VA at 6 Months & Frequency & Total \\
\hline$<6 / 36$ & 2 & $3.34 \%$ \\
$6 / 36-6 / 18$ & 10 & $16.66 \%$ \\
$6 / 18-6 / 12$ & 16 & $26.66 \%$ \\
$6 / 12-6 / 9$ & 32 & $53.34 \%$ \\
Total & 60 & $100 \%$ \\
\hline
\end{tabular}

Table 5: OCT at 6 Months ( $\mathrm{n}=60$ eyes).

\begin{tabular}{|lcc|}
\hline OCT at 6 Months & Frequency & Total \\
\hline$>500 \mu$ & 2 & $3.33 \%$ \\
$400-500 \mu$ & 12 & $20.00 \%$ \\
$300-400 \mu$ & 38 & $63.33 \%$ \\
$200-300 \mu$ & 8 & $13.34 \%$ \\
Total & 60 & $100 \%$ \\
\hline
\end{tabular}

Mean OCT 6 months was $327.44 \mu$ with $\mathrm{SD} \pm 55.55 \mu$

Efficacy of intra-vitreal bevacizumab in causing improvement in VA was analyzed as bevacizumab was effective in $49(81.67 \%)$ patients and efficacy of intra-vitreal bevacizumab in causing reduction in macular thickness was analyzed as bevacizumab was effective in $42(70.00 \%)$ patients (table 6 and table 7$)$.

Table 6: Efficacy Regarding VA ( $\mathrm{n}=60$ eyes).

\begin{tabular}{|lcc|}
\hline Efficacy & Frequency & Percentage \\
\hline Yes & 49 & $81.67 \%$ \\
No & 11 & $18.33 \%$ \\
Total & 60 & $100 \%$ \\
\hline
\end{tabular}

The mean number of intra-vitreal injections required per 6 months were $3.87 \pm 0.54$ whereas the re- treatment rate of intravitreal bevacizumab after first 3 injections was $24.6 \%$.

Table 7: Efficacy Regarding OCT ( $\mathrm{n}=60$ eyes).

\begin{tabular}{|lcc|}
\hline Efficacy & Frequency & Percentage \\
\hline Yes & 42 & $70.00 \%$ \\
No & 18 & $30.00 \%$ \\
Total & 60 & $100 \%$ \\
\hline
\end{tabular}

\section{DISCUSSION}

Different studies have reported that repeated intravitreal anti-vascular endothelial growth factor treatments are associated with significant improvements at six months, and no significant safety concerns relating to the drug were identified in this time. Our study also showed that the first intra-vitreal injection of bevacizumab was associated with significant improvement visually and anatomically. The mean improvement was 0.24 after first injection with a further improvement of 0.30 after 6 months. In the Branch retinal vein occlusion (BRVO) study, six monthly intraocular injections of $0.3 \mathrm{mg}$ or $0.5 \mathrm{mg}$ of ranibizumab provided rapid anatomic and visual improvements in patients with $\mathrm{BRVO}^{9,10}$. Ranibizumab or bevacizumab for macular edema secondary to BRVO may have similar efficacy for improving the VA.

Branch retinal vein occlusion is associated with decreased perfusion of retinal cells resulting in hypoxia. This hypoxia causes increased release of VEGF, which increases vascular permeability resulting in vascular leakage. Intra-vitreal bevacizumab is a vascular endothelial growth factor inhibitor which causes a rapid improvement in macular edema but repeated injections are usually required to maintain this effect ${ }^{11,12}$. The transient nature of the effect of bevacizumab may be explained by the short intravitreal half-life of $1.25 \mathrm{mg}$ (approximately 3 days), resulting in a rapid reduction in the intra-ocular concentration of the drug11. Several studies have suggested that in ischemic BRVO the amount of nonperfused areas are associated with the severity of macular edema. Noma et al. reported in their study that there is a positive correlation between the amount of macular edema measured on OCT and nonperfused area size ${ }^{13,14}$. Significant improvements in macular edema secondary to BRVO have been reported after intra-vitreal bevacizumab injections ${ }^{15}$. Bevacizumab may not require monthly injections to 
gain an optimal therapeutic response. An early report of intra-vitreal anti-VEGF agents in animal models suggested that bevacizumab has a longer intra-vitreal half-life than ranibizumab. In rabbits, the vitreous half-life of ranibizumab is 2.88 days while it is 4.32 days for bevacizumab ${ }^{16,17}$. Although there is no clinical evidence that patients receiving bevacizumab for retinal disease require less frequent injections than patients receiving ranibizumab, Epstein and coworkers $^{23}$ achieved the same visual improvement in response to intra-vitreal bevacizumab injections administered every 6 weeks for central retinal vein occlusion as that obtained after ranibizumab administered every 4 weeks in the treatment of macular edema after central retinal vein occlusion ${ }^{18-20}$.

\section{CONCLUSION}

Intra-vitreal bevacizumab is an effective treatment for macular edema caused by BRVO in terms of both anatomic and visual improvement.

\section{Author's Affiliations}

Dr. Imran Ahmad

MBBS, FICO, FCPS,

Assistant Professor, Department of Ophthalmology, Gajju Khan Medical College/Bacha Khan Medical Complex, Swabi.

Dr. Mubashir Rehman

MBBS, FCPS.

Assistant Professor, department of Ophthalmology, Nowshera Medical College/Qazi Hussain Ahmad Medical Complex, Nowshera.

Prof. Mir Ali Shah

MBBS, FCPS.

Associate Professor, department of Ophthalmology, Postgraduate Medical Institute, Lady Reading Hospital Peshawar.

Dr. Irfan Aslam Khattak

MBBS, FCPS.

Vitreo-retina Trainee, Department of Ophthalmology, Hayat Abad Medical Complex, Peshawar.

\section{Author's contribution}

Dr. Imran Ahmad

Patient's selection, Data collection, results and discussion
Dr. Mubashir Rehman

Patient's selection, Data collection, results and discussion

Prof. Mir Ali Shah

Patient's selection, Data collection, results and discussion

Dr. Irfan Aslam Khattak

Literature search

\section{REFRENCES}

1. Klein R, Moss SE, Meuer SM, Klein BE. The 15-year cumulative incidence of retinal vein occlusion: the BeaverDam Eye Study. Arch Ophthalmol. 2008; 126: 513-8.

2. Wu L, Arevalo JF, Roca JA, Maia M, Berrocal MH, Rodriguez FJ, Evans T, Costa RA, Cardillo J. Comparison of two doses of intravitreal bevacizumab (Avastin) for treatment of macular edema secondary to branch retinal vein occlusion: results from the PanAmerican Collaborative Retina Study Group at 6 months of follow-up. Retina. 2008; 28: 212-9.

3. Rehak J, Rehak M. Branch retinal vein occlusion: pathogenesis, visual prognosis, and treatment modalities. Curr Eye Res. 2008; 33: 111-31.

4. Rogers S, McIntosh RL, Cheung N, et al. The prevalence of retinal vein occlusion: pooled data from population studies from the United States, Europe, Asia, and Australia. Ophthalmology, 2010; 117: 313-9.

5. Campochiaro PA, Hafiz G, Shah SM, et al. Ranibizumab for macular edema due to retinal vein occlusions: implication of VEGF as a critical stimulator. Mol Ther. 2008; 16: 791-9.

6. Noma H, Funatsu H, Yamasaki M, et al. Aqueous humour levels of cytokines are correlated to vitreous levels and severity of macular oedema in branch retinal vein occlusion. Eye (Lond), 2008; 22: 42-8.

7. Yilmaz T, Cordero-Coma M. Use of bevacizumab for macular edema secondary to branch retinal vein occlusion: a systematic review. Graefes Arch Clin Exp Ophthalmol. 2012; 250: 787-93.

8. Ehlers JP, Decroos FC, Fekrat S. Intravitreal bevacizumab for macular edema secondary to branch retinal vein occlusion. Retina. 2011; 31: 1856-62.

9. Brown DM, Campochiaro PA, Bhisitkul RB, et al. Sustained benefits from ranibizumab for macular edema following branch retinal vein occlusion: 12-month outcomes of a phase III study. Ophthalmology, 2011; 118: 1594-602.

10. Chen CH, Chen YH, Wu PC, Chen YJ, Lee JJ,Liu YC \&Kuo HK. Treatment of branch retinal vein occlusion induced macularedema in treatment-naive cases with a single intravitreal triamcinolone or bevacizumab injection. Chang Gung Med J. 2010; 33: 424-35.

11. Beer PM, Wong SJ, Hammad AM, Falk NS,O'Malley MR \& Khan S. Vitreous levels of unbound 
bevacizumab and unbound vascular endothelial growth factor in two patients. Retina. 2006; 26: 871-6.

12. Noma $\mathbf{H}$, Funatsu $\mathbf{H}$, Mimura $\mathbf{T}$ \& Shimada $K$. Influence of ischaemia on visual function in patients with branch retinal vein occlusion and macular edema. Clin Ophthalmol. 2011; 5: 679-685.

13. Donati S, Barosl P, Bianchi $\mathbf{M}$, et al. Combined intravitreal bevacizumab and grid laser photocoagulation for macular edema secondary to branch retinal vein occlusion. Eur J Ophthalmol. 2012; 22: 607-14.

14. Bakri SJ, Snyder MR, Reid JM, et al. Pharmacokinetics of intravitreal ranibizumab (Lucentis). Ophthalmology, 2007; 114: 2179-82.

15. Brown DM, Campochiaro PA, Signh RP, et al. The CRUISE investigators Ranibizumab for macular edema following central retinal vein occlusion: six-month primary end point results of a phase III study. Ophthalmology, 2010; 117: 1124-33.

16. Hayreh SS, Zimmerman MB. Branch retinal vein occlusion: natural history of visual outcome. JAMA Ophthalmol. 2014; 132: 13-22.

17. Rogers SL, McIntosh RL, Lim L, Mitchell P, Cheung N, Kowalski JW, Nguyen HP, Wang JJ, Wong TY. Natural history of branch retinal vein occlusion: an evidencebased systematic review. Ophthalmology, 2010; 117: 1094-1101.

18. Liu H, Li S, Zhang Z, Shen J. Predicting the visual acuity for retinal vein occlusion after ranibizumab therapy with an original ranking for macular microstructure. Exp Ther Med. 2018; 15: 890-896.

19. Mitry D, Bunce C, Charteris D. Anti-vascular endothelial growth factor for macular oedema secondary to branch retinal vein occlusion. Cochrane Database Syst Rev. 2013; 31: 951-957.

20. Ivanovska Adjievska B, Boskurt S, Orovcanec N, Dimovska-Jordanova V. The outcome of low-frequency intravitreal bevacizumab therapy for macular edema in retinal vein occlusions. Clin Ophthalmol. 2017; 11: 11831190. 